\title{
ABSTRACTS
}

\section{THE LARYNX.}

Two Abnormal Laryngeal Muscles. LaWrence H. Well.S and EdriC A. Thомаs. (Journal of Anatomy, April 1927, Vol. 1xi., p. 340.)

The larynx was obtained from the body of a Zulu, aged 69, in whom numerous other anatomical abnormalities were discovered. The first muscle arose in continuity with the origin of the posterior cricoarytenoid muscle, from the uppermost part of the depression lateral to the median ridge on the posterior aspect of the left lamina of the cricoid.

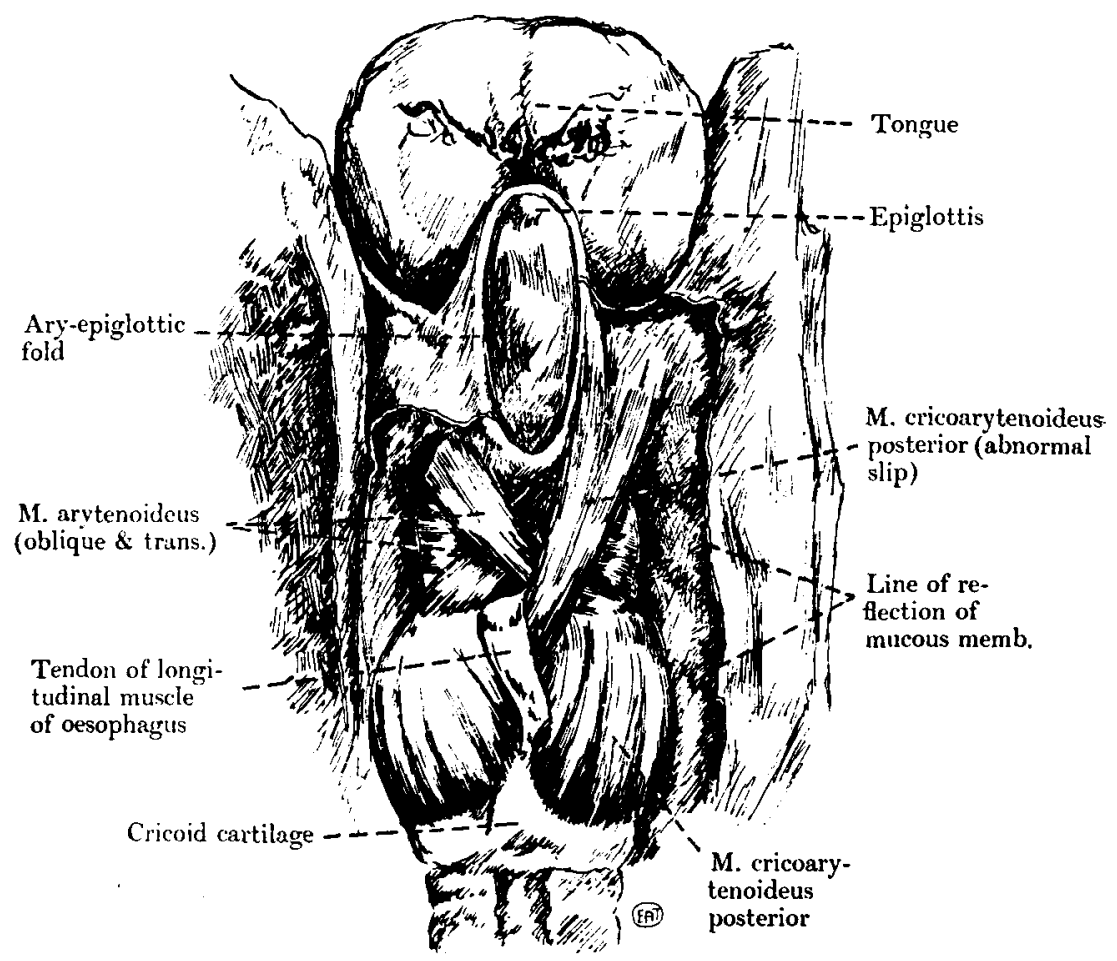

cartilage. From this origin the muscle passed upwards and laterally, superficial to the oblique and transverse arytenoid muscles, to find its principal insertion, in common with the oblique arytenoid muscle, into the apex of the arytenoid cartilage. It was innervated by a twig from the posterior division of the inferior laryngeal nerve.

The second muscle was found on the left lateral aspect of the larynx, under cover of the left lamina of the thyroid cartilage. It 


\section{Abstracts}

arose from the left supero-lateral angle of the lamina of the cricoid cartilage under cover of the lateral crico-arytenoid muscle, and passed upwards and anteriorly, lying superficial to the thyro-arytenoid and thyro-epiglottic muscles, to be inserted into a thickened band of fascia

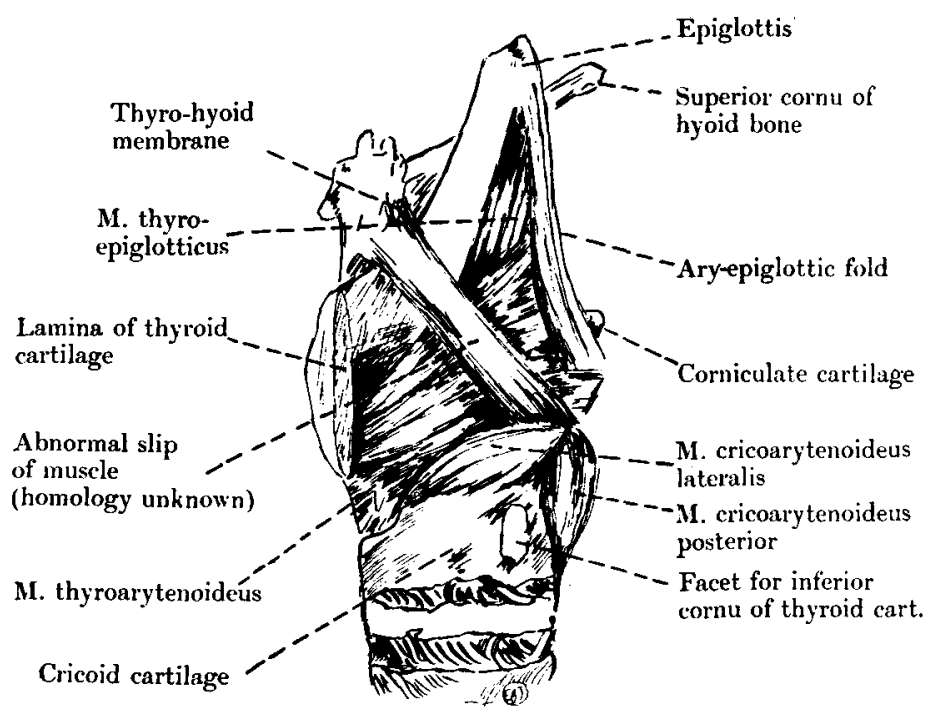

which appeared to be continued above into the lateral part of the middle thyro-hyoid ligament. It was innervated by the anterior branch of the inferior laryngeal nerve.

The man having suffered from tuberculosis the throat had been carefully examined and the larynx was described in the clinical notes as normal. No difficulty of speech was observed.

T. B. Layton.

Importance of Early Diagnosis and Treatment of Laryngeal Tuberculosis. Frank R. Spencer, M.D., Boulder, Colo. (Journ. Amer. Med. Assoc., No. 4, 24th July I926, Vol. lxxxvii., p. 216).

The author discusses the subject with great detail and states, " most patients with early laryngeal tuberculosis complain of a slight huskiness of the voice alter getting up in the morning. This may be relieved by clearing the throat, by coughing, or by talking. Later on it may be more persistent and last half or all of each day. The patient is conscious of a greater effort in talking and realises that the larynx becomes tired easily." These are the "danger signals."

Early laryngeal examination is urged in all tuberculous cases; vascular changes are often noted before actual laryngeal changes are noted. The general pallor of the mucous membrane of the entire 


\section{The Larynx}

respiratory tract is very suggestive, and there are often pinkish-red mottled areas dotting the pale mucosa of the larynx. Infiltration over the posterior laryngeal wall is a common early sign. Ulcers are usually superficial and are late in appearance; they may be more easily recognised by spraying with $\mathbf{x}$ or 2 per cent. aqueous solution of fluorescin, which makes them appear green. CEdema, if at all extensive, is late and more likely to be seen in the arytenoid region. Extensive infiltration of the epiglottis, arytenoids, false or true cords, appears late. Pain, perichondritis, necrosis, and notches in the epiglottis are very late signs.

A table is given showing the differential diagnosis between syphilis, actinomycosis, carcinoma, chronic catarrhal laryngitis, papilloma, granuloma and lupus. Stress is laid on the importance of general physical examination, with special attention to the chest.

A high altitude is recommended as stimulating phagocytosis. Absolute silence is urged, preferably requiring the patient to use a pencil and writing pad. Heliotherapy, by means of a Verba solar laryngoscope, is also recommended. The author favours lactic acid applications of from 5 to $3^{\circ}$ per cent. to ulcers. Cautery is recommended as the best single method of treatment. For pain, 2 or 3 per cent. cocain solution or 20 per cent. chaulmoogra oil may be used; if severe, the superior laryngeal nerve on both sides should be injected. Amputation of the epiglottis with a cold wire snare is recommended in late cases.

In discussing the paper, Dr Hastings, Los Angeles, stated that he had never had any results from removing the epiglottis. Dr Joseph Beck, Chicago, urged the use of the carbon lamp and biopsy, if there is any doubt of malignancy, as he had cases where laryngectomy was performed on a tuberculous patient who had neither cancer nor syphilis. Dr M. B. Brown, Denver, recommended gastrostomy when swallowing became impossible from pain, and cited 7 cases, one of whom died within a few hours, several lived for months, and one lived in comfort for over a year and gained 35 pounds.

Angus A. Campbell.

Pathological-Anatomical Investigations on Laryngeal Tuberculosis. A. Esch (Leipzig). (Zeitschrift für Hals- Nasen- und Ohrenheilkunde, First Part, Band xvii., Heft 2, p. 222 ; Second Part, Band xvii., Heft 4, p. 530.)

In this searching investigation the writer approaches the somewhat neglected question of the development of the earliest beginnings of laryngeal tuberculosis.

A special method of examination is employed, the larynx being divided by a transverse vertical cut into a posterior portion containing VOL. XLII. NO. IX. 


\section{Abstracts}

the bulk of the vocal cords, and an anterior one with the epiglottis and anterior commissure. Further sub-division, imbedding, hardening, and serial section permitted of exceptionally minute examination.

$\mathrm{He}$ first examined microscopically a series of larynges from subjects not affected with tuberculosis but who had coughed a great deal during the latest part of their life. The changes were those that irritation was likely to cause, such as, here and there, metaplastic pavement epithelium extending into the submucosa, and in places infiltration with lymphocytes and isolated plasma cells. This is most marked around the ducts of the secreting glands. He then microscoped ten larynges in persons suffering from pulmonary tuberculosis which to the naked eye were normal. Of these only two were free from histological evidence of tuberculosis, one being absolutely normal, the other showing only the changes induced by excessive coughing. In the other eight the evidence of tuberculosis was unquestionable, and was in some cases most obvious in the ventricle of Morgagni and the posterior part of the pyriform fossa. The changes only extended in depth along the excretory ducts of the glands. On the posterior wall the layers of pavement epithelium were increased. Minute spots of loss of epithelium were found by the microscope. The diagnosis was confirmed by the detection of one or more giant cells. The writer emphasises the want of correspondence between the laryngeal and pulmonary lesions, the latter presenting necrotic features, the former "productive." The importance of not mistaking this condition for phonasthenia is obvious.

In the second part of his communication Esch studies ten larynges showing more or less extensive naked-eye changes in the subjects of pulmonary tuberculosis. In those with the slighter changes there were no definite situations affected, but in the more extensive the sites of predilection were generally involved, namely the posterior wall, vocal cords, aryepiglottic folds and epiglottis, and in every case the vocal processes down to the cartilage. The process of "cartilage resorption" and its replacement by fibrous tissue are described. If the cartilage has become calcified it is either extruded as a foreign body if the hyaline surroundings are completely destroyed, or replaced by bone if the infectious process is overcome.

James Dundas-Grant.

\section{Tuberculosis of the Larynx and Artificial Pneumothorax. St Cla1R}

Thomson and Richard R. Trail. (Lancet, 1927, Vol. i., p. 963.)

The authors conclude that ( $\mathrm{I}$ ) cases of pulmonary tuberculosis are always rendered much more serious by the addition of a laryngeal extension. (2) This complication is of still worse augury if it develops after admission to a sanatorium or after induction of an artificial pneumothorax. (3) Despite this experience, the presence of laryngeal 


\section{The Larynx}

tuberculosis is no contraindication to this operation, but it may speedily effect a cure or render the galvano-cautery or other treatment more promising. (4) The larynx can be cured by this measure, even although bacilli may continue to be present in the sputum and mischief to be detectable in the chest. (5) The indications for induction of artificial pneumothorax must, primarily, be based on the pulmonary and general condition of the patient. So far as the larynx is concerned the only contraindication would be an acute, miliary invasion.

MaCleod YearsLey.

\section{Tuberculous Infection of the Respiratory Tract and its Treatment by the Physician and the Laryngologist. L. DE Reynier. (Archives Internationales de Laryngologie, April Ig27.)}

The modern tendency of ultraspecialisation is a mistake. This particularly applies to diseases of the lungs and of the upper respiratory tract. These anatomical regions have a close bond in common, and it would be committing a grave error to neglect to consider these diseases in relation the one to the other.

The paper is divided into three principal sections. The first deals with the rôle of the laryngologist in so-called "latent pulmonary tuberculosis." The second deals with the modern treatment of declared pulmonary tuberculosis. The third deals with the effect which affections of the lungs have on those of the upper respiratory tract, and vice versâ.

Many cases of slight pyrexia, cough, and hæmoptysis are due to affections of the accessory sinuses and upper respiratory tract, and are frequently and erroneously labelled by the physician as pulmonary tuberculosis.

On the other hand, cases of adductor laziness of the vocal cords should place the laryngologist on the "qui vive" for an affection of the lungs.

The author draws attention to some important points in distinguishing between hæmoptysis originating from the lungs, and that originating from atelectased pharyngeal vessels. In the former case, the hæmoptysis at first consists of clear blood, which when repeated in the course of a few hours or days becomes brown to black. Blood from this source does not dissolve in water. Whereas, in the case of hæmorrhage from the pharynx, hæmoptysis occurs daily in the morning, and the blood dissolves immediately in a little water.

In the next section, the author proceeds to give a résumé of the modern treatment of pulmonary tuberculosis. The gist of his remarks is that no specific cure, as has been claimed for "Sanochrysin," has yet been found. Hygienic treatment in a sanatorium still remains the foundation upon which our treatment should be based. 


\section{Review of Book}

In the last section, the author states that the evolution of a tuberculous lesion of the upper respiratory tract is entirely independent of the evolution of a tuberculous infection of the lungs. When treated on surgical lines, the laryngeal lesion can almost always be cured even if the lung condition increases in severity. On the other hand, any treatment which acts favourably upon the condition of the lungs will operate favourably upon the lesion of the upper respiratory tract.

Finally, the author draws attention to the importance of a clear nasal airway in preventing or improving a tuberculous infection of the lower respiratory tract.

Michaki Vlasto.

The Treatment of Laryngeal Tuberculosis in Sanatoria. C. D. PARFITT, M.D., C.M. (Canadian Medical Association Journal, October г 926 , p. I 206.)

The author presents statistics from various sources to show the relative frequency of laryngeal involvement in patients with pulmonary tuberculosis. The statistics of Sir St Clair Thomson, indicating that the prognosis is relatively much worse where a laryngeal complication is present, are also quoted.

Parfitt is a strong advocate of active local treatment rather than dependence on the local results of the improved general condition under sanatorium treatment.

$\mathrm{He}$ has found the best result from treatment by galvano-cautery as opposed to other operative methods.

The technique of anæsthesia employed is described in detail.

E. Hamilton White.

\section{REVIEW OF BOOK}

The Medical Annual: a Year Book of Treatment and Practitioner's Index. Forty-fifth year. 1927. Bristol: John Wright \& Sons, Ltd. London: Simpkin, Marshall, Hamilton, Kent \& Co., Ltd. 624 pages.

The reviewer desiring to consult an article on tracheotomy which he had read in the Lancet a year and a half ago, wisely referred to the recent issue of the Medical Annual, and found at once the article so faithfully abstracted by $\mathrm{Mr}$ Wright that no further search was necessary. This is a typical incident, and we cannot offer better advice to those in search of articles they have read and desire to read again than that they should appeal to the Medical Annual before looking elsewhere. They will often save themselves from much trouble by so doing. Readers of 